\title{
Vascular mechanisms in the pathophysiology of human spinal cord injury
}

Charles H. Tator, M.D., Ph.D., F.R.C.S.(C), and Izumi Koyanagi, M.D.

Canadian Paraplegic Association Spinal Cord Injury Research Laboratory, Division of Neurosurgery and Playfair Neuroscience Unit, The Toronto Hospital, Western Division, and the University of Toronto, Toronto, Ontario, Canada

Vascular injury plays an important role in the primary and secondary injury mechanisms that cause damage to the acutely traumatized spinal cord. To understand the pathophysiology of human spinal cord injury, the authors investigated the vascular system in three uninjured human spinal cords using silicone rubber microangiography and analyzed the histological findings related to vascular injury in nine acutely traumatized human spinal cords obtained at autopsy. The interval from spinal cord injury to death ranged from 20 minutes to 9 months. The microangiograms of the uninjured human cervical cords demonstrated new information about the sulcal arterial system and the pial arteries. The centrifugal sulcal arterial system was found to supply all of the anterior gray matter, the anterior half of the posterior gray matter, approximately the inner half of the anterior and lateral white columns, and the anterior half of the posterior white columns. Traumatized spinal cord specimens in the acute stage (3-5 days postinjury) showed severe hemorrhages predominantly in the gray matter, but also in the white matter. The white matter surrounding the hemorrhagic gray matter showed a variety of lesions, including decreased staining, disrupted myelin, and axonal and periaxonal swelling. The white matter lesions extended far from the injury site, especially in the posterior columns. There was no evidence of complete occlusion of any of the larger arteries, including the anterior and posterior spinal arteries and the sulcal arteries. However, occluded intramedullary veins were identified in the degenerated posterior white columns. In the chronic stage (3-9 months postinjury), the injured segments showed major tissue loss with large cavitations, whereas both rostral and caudal remote sites showed well-demarcated necrotic areas indicative of infarction mainly in the posterior white columns. Obstruction of small intramedullary arteries and veins by the initial mechanical stress or secondary injury mechanisms most likely produced these extensive white matter lesions. Our studies implicate damage to the anterior sulcal arteries in causing the hemorrhagic necrosis and subsequent central myelomalacia at the injury site in acute spinal cord injury in humans.

Key Words * acute spinal cord injury * vascular lesion * pathology * humans

Intensive studies of the pathophysiology of spinal cord injury have provided evidence that the primary mechanical trauma is followed by secondary injury mechanisms that contribute to the necrotizing process and that vascular injuries play a key role in both primary and secondary damage.[26,38-40] For example, experimental studies have reported significant posttraumatic ischemia at the injured segment and 
adjacent areas after severe spinal cord injury.[9,10,13,32,33] Using microangiographic techniques, regions of severe ischemia were demonstrated in the traumatized spinal cord in rats, $[20,21,34,45]$ cats, $[1,5,7,31]$ rabbits, $[8,27,44]$ and monkeys.[11] The pathophysiology of vascular mechanisms of secondary neural injury was the topic of a recent review.[37]

In the present study, we investigated the vascular system in three uninjured human cervical spinal cords using silicone rubber microangiography. This technique allows three-dimensional analysis of the intramedullary vessels after the spinal cord is made transparent with an alcohol-methylsalicylate technique.[21] The present study is the first to use this technique to visualize the vascular system in the human spinal cord. It was believed that this technique would provide useful information for interpreting vascular damage in acute spinal cord injury, especially the phenomena of secondary injury and remote infarction. In addition, we analyzed histological findings in nine traumatized human spinal cords obtained at autopsy. The purpose of these studies was to determine the role of vascular injuries in the pathophysiology of human spinal cord injury.

\section{MATERIALS AND METHODS}

\section{Silicone Rubber Angiography in the Uninjured Human Spinal Cord}

Uninjured human spinal cords were removed at the cervical level from three cadavers during autopsy to examine the normal vascular system using the silicone rubber microangiographic technique. These three individuals, aged 62 to 77 years old, had had no spinal cord lesions and died of cerebrovascular accidents or pneumonia. The interval from death to autopsy ranged from 18 to 66 hours. Before removing the spinal cord, the left vertebral artery was cannulated at its origin at the subclavian artery and was infused with 800 to $1000 \mathrm{ml}$ saline. The spinal cord was then removed from C-2 to T-2 (two cases) or from C-4 to $\mathrm{T}-2$ (one case) by means of an anterior approach.

The C-5 anterior radiculomedullary artery was cannulated with a tapered PE-50 tubing under a dissecting microscope. The cut ends of the anterior spinal artery and other radiculomedullary arteries transected during removal of the cords were then ligated with No. 6-0 nylon or No. 4-0 silk. Silicone rubber (Microfil; Flow Tek., Inc., Boulder, CO) was prepared immediately before injection. The spinal cord was perfused with 1 to $5 \mathrm{ml}$ of saline from the PE-50 tubing and 0.7 to $1 \mathrm{ml}$ of silicone rubber was injected manually through a $1-\mathrm{ml}$ syringe for approximately 5 minutes. Following the silicone rubber injection, the spinal cords were stored in a refrigerator overnight, after which they were immersed in $10 \%$ buffered formalin for at least 3 weeks.

The vasculature on the surface of the spinal cord was inspected using a dissecting microscope. The cord was dehydrated with alcohol and immersed in methylsalicylate, which rendered the tissue transparent. The cord was then cut transversely or coronally into 2-mm slices with a razor blade. The cord slices were immersed in methylsalicylate in a petri dish, and the intramedullary vasculature was inspected through a microscope. The course of the intramedullary vessels could be tracked by changing the microscopic focus, which allowed a three-dimensional analysis of the vessels in these 2-mm thick sections. 
TABLE 1

CINICAL FEATURES, SURGKAL TREATMENT, AND CAUSE OF DEATH IN NINE CASES

OF ACUTE SPINAL CORD INURV

\begin{tabular}{|c|c|c|c|c|c|c|c|}
\hline Cas & $\begin{array}{l}\text { Age } \\
\text { (yis), } \\
\text { Sex }\end{array}$ & $\begin{array}{l}\text { Cause of } \\
\text { Iri ury }\end{array}$ & $\begin{array}{l}\text { Level \& } \\
\text { Type of } \\
\text { Iri ury }\end{array}$ & $\begin{array}{c}\text { Clirical } \\
\text { State }\end{array}$ & $\begin{array}{l}\text { Sugical } \\
\text { Treatment }\end{array}$ & $\begin{array}{c}\text { Cause of } \\
\text { Death }\end{array}$ & $\begin{array}{l}\text { Interval } \\
\text { From Injury } \\
\text { to Death }\end{array}$ \\
\hline 1 & $10, M$ & TÁ & C1-2 OF & $\mathrm{CCl}$ & none & high cervical $\mathrm{Cl}$ & $20 \mathrm{~min}$ \\
\hline 2 & $39, \mathrm{M}$ & TÁ & C4-5 AD & $\mathrm{CCl}$ & $\begin{array}{l}\text { open reduction, } \\
\text { c4-5 laminectom } y_{1} \\
\text { perfusion \& m yelo- } \\
\text { tom y, posterior fusion }\end{array}$ & $\begin{array}{l}\text { trainstem infarct due } \\
\text { to traum atic ocdu- } \\
\text { sion of rt VA }\end{array}$ & 3 days \\
\hline 3 & $79, \mathrm{~F}$ & Тम & C4-5 FD & $\mathrm{ICl}$ & none & $\begin{array}{l}\text { trainstem infarct due } \\
\text { to traum atic ocdu- } \\
\text { sion of It VA }\end{array}$ & 5 days \\
\hline 4 & $37, M$ & di ving & c-7 bfract & $\mathrm{CCl}$ & none & APE & 17 days \\
\hline 5 & $65, \mathrm{~F}$ & TA & C1-2 AAD & $\mathrm{CCl}$ & none & $\mathrm{AB}$ & 18 days \\
\hline 6 & $56, M$ & & $\mathrm{C}-5 \mathrm{FD}$ & $\mathrm{Cl}$ & none & $\mathrm{AB}$ & $3 \mathrm{mos}$ \\
\hline 7 & $72, \mathrm{~F}$ & Тд̈ & $C 5-6 \mathrm{FD}$ & $\mathrm{Cl}$ & posterior fusion & $\mathrm{AB}$ & $3 \mathrm{mos}$ \\
\hline 8 & $52, \mathrm{M}$ & Тд̈ & $5-6 \mathrm{AD}$ & $\mathrm{CCl}$ & none & & $7 \mathrm{mos}$ \\
\hline 9 & $70, \mathrm{~F}$ & fall & $\bigcirc 1$ & $\mathrm{CCl}$ & posterior fusion & $\mathrm{AB}$ & $9 \mathrm{mos}$ \\
\hline \multicolumn{8}{|c|}{ 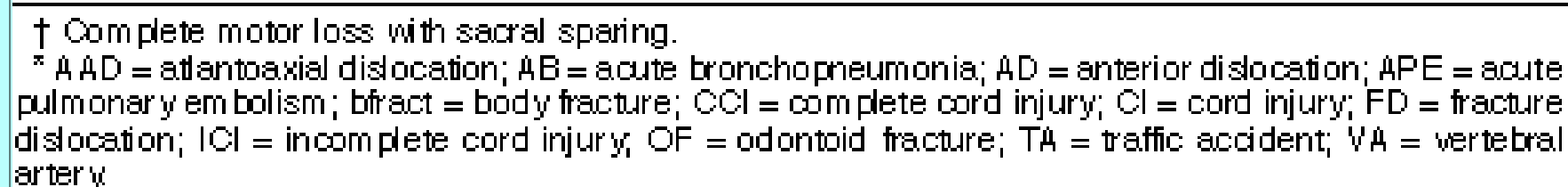 } \\
\hline
\end{tabular}

\section{Histological Analysis of Acute Human Spinal Cord Injury}

To investigate the vascular changes that occur in acute spinal cord injury, the histological findings in the acutely traumatized spinal cords of nine autopsy cases were analyzed. These nine patients, who were aged 10 to 79 years when they died, had suffered complete or incomplete cord injury at the cervical level (Table 1). One patient died immediately after he had sustained a high cervical cord injury in a traffic accident. The other eight patients died of pneumonia, pulmonary embolism, or brainstem infarction 3 days to 9 months after they had sustained cervical trauma (Table 1). The spinal cord specimens were stained with hematoxylin and eosin for general features and luxol fast blue stain for myelinated axons.

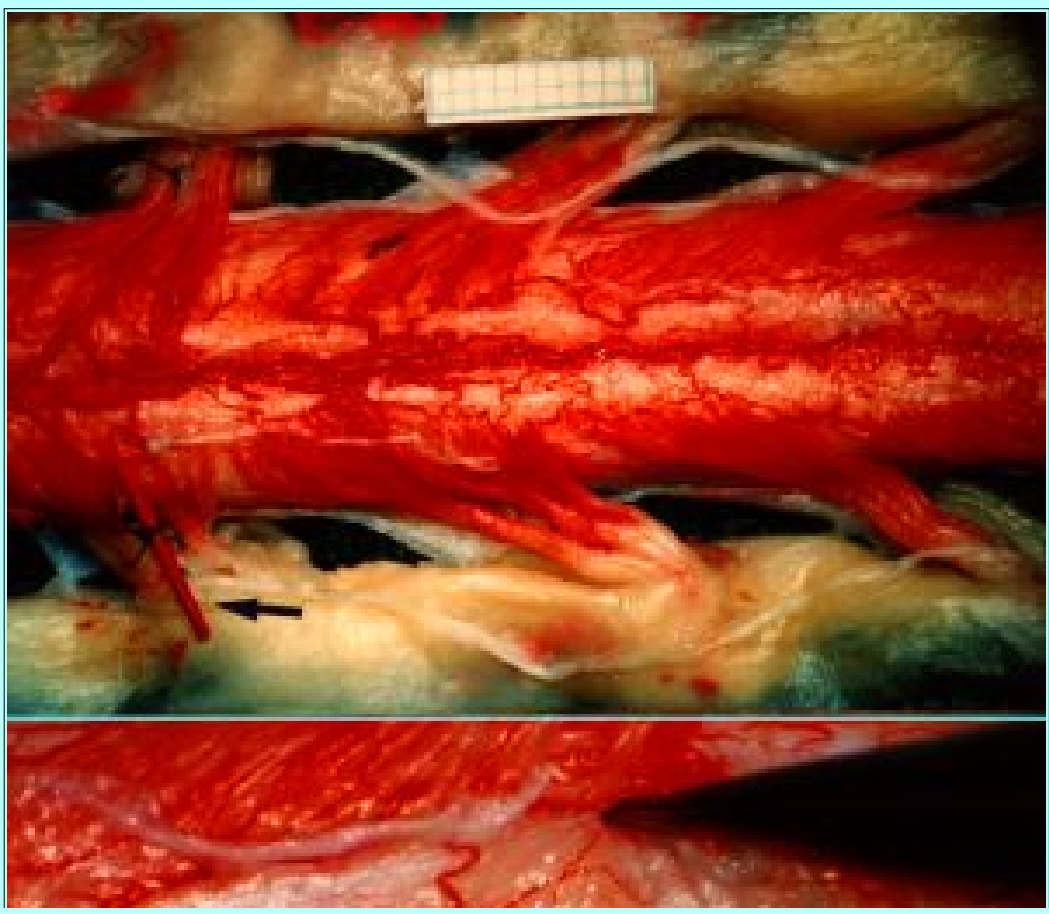

Fig. 1. Postmortem photographs of nontraumatized spinal cord. Upper: The anterior surface of the cervical cord. The rostral end is to the left. Silicone rubber was injected into the $\mathrm{C}-5$ radiculomedullary artery through tapered PE-50 tubing (arrow). The arterial and venous channels over the spinal cord surface are almost completely filled with silicone rubber. Center: The anterior surface and anterior median sulcus of the cervical cord after silicone rubber injection. The pia mater, which covers the anterior spinal artery and vein, has been divided. The rostral end is to the left. The forceps are holding the pia mater on the anterior surface to open the anterior median 


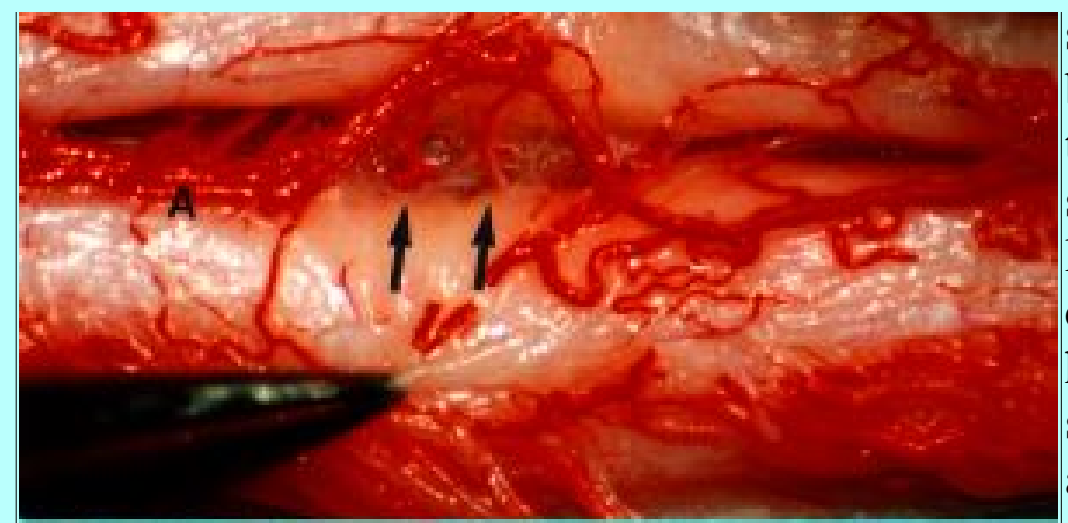

sulcus where the sulcal arteries are seen as branches of the anterior spinal artery (A). At the posterior end of the anterior median sulcus, the sulcal arteries (arrows) course laterally in front of the anterior white commissure and enter either the right or left half of the spinal cord. Lower: Lateral surface of the spinal cord at the C7-8 level after silicone rubber injection. The anterior spinal artery (A) gives rise to a lateral

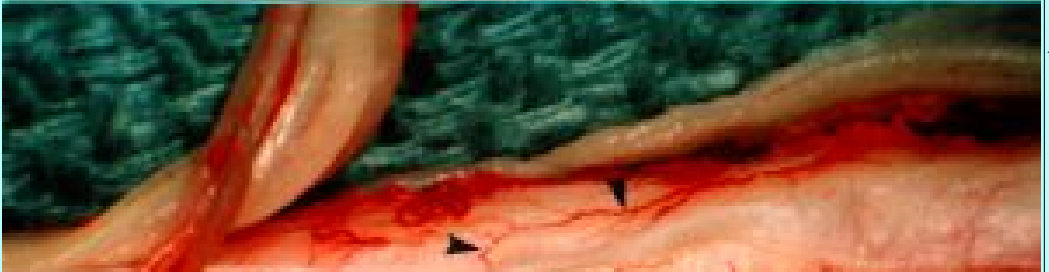
branch (arrow), which then courses over the anterior and lateral surfaces of the cord. Subsequently, this branch extends subpially (lower arrowhead) under the dentate ligament, which can be discerned as the faint white structure (D), and then communicates with a small branch from the posterior spinal artery (upper two arrowheads).

\section{RESULTS}

\section{Vascular System in the Nontraumatized Cervical Cord}

Most of the arterial system on the surface of the nontraumatized spinal cord was completely filled with the silicone rubber (Fig. 1 upper), although segments of the posterior spinal arteries were only partially filled in two of the cords. Two of the cords also showed filling of the venous channels on the surface of the cords.

Anterior Surface. The outer layer of the pia mater was found to cover the anterior spinal artery and vein on the anterior surface. Two to six anterior radiculomedullary arteries fed the anterior spinal artery in the examined segments. The anterior spinal artery consisted of a single trunk in one spinal cord and divided into two vessels for a short distance in the other two spinal cords. The anterior spinal artery gave rise to sulcal arteries, which travelled in the anterior median sulcus, and also a few small caliber lateral branches, which travelled over the anterior surface of the spinal cord. The sulcal arteries ran into the anterior median sulcus and travelled in a slightly rostral direction to enter either the left or right half of the spinal cord (Fig. 1 center). Usually a sulcal artery supplied only one side of the cord with the adjacent sulcal artery supplying the other side. A small number of sulcal arteries were found to supply both sides of the spinal cord. The mean number of sulcal arteries per centimeter of cord in the examined segments was 4.6 (Table 2). There was overlap in the supply so that each segment of gray matter contained capillaries branching from two to three sulcal arteries. These features could be appreciated three-dimensionally in the cleared specimens. In the anterior sulcus, the sulcal arteries often had small direct branches to the medial anterior white columns. Bifurcation of the sulcal artery was common in the anterior sulcus: 13 to $28 \%$ (mean 19\%) of the sulcal arteries bifurcated in the anterior median sulcus. These bifurcated sulcal arteries frequently supplied the spinal cord bilaterally, although each branch supplied only one-half of the cord (Table 2). 


\begin{tabular}{|c|c|c|c|c|}
\hline \multicolumn{5}{|c|}{$\begin{array}{c}\text { TABLE } 2 \\
\text { SUL CAL ARTERIES \& LATERAL BRANCHES OF THE ANTERIOR SPINAL ARTERV IN } \\
\text { THREE UN NURED HUMAN SPINAL CORDS }\end{array}$} \\
\hline \multirow[b]{2}{*}{ Factor } & \multicolumn{4}{|c|}{ Uninjured Spinal Cord } \\
\hline & Case 1 & Case 2 & Case 3 & Mean \\
\hline cord length (cm) & $\begin{array}{c}7.0 \\
\text { C-T1 }\end{array}$ & 11.2 & $\begin{array}{c}4.4 \\
4-\infty\end{array}$ & 7.5 \\
\hline $\begin{array}{l}\text { no. of SAs in cord specimen } \\
\text { no. of SAstm }\end{array}$ & $\begin{array}{l}29 \\
4.1\end{array}$ & & $\begin{array}{l}23 \\
5.2\end{array}$ & $\begin{array}{l}33.7 \\
4.6\end{array}$ \\
\hline no. of bifurcated SAs (\%)† & 8 (28) & $8(16)$ & $3(13)$ & $6.3(19)$ \\
\hline bilat supply (no of SAs) S & 4 & 5 & 3 & \\
\hline no. of LBs in cord specimen & 7 & 21 & 8 & 12 \\
\hline no. of LE & 1.0 & 1.9 & 1.8 & 1.6 \\
\hline \multicolumn{5}{|c|}{$\begin{array}{l}\text { "LB = lateral tranch of the anterior spinal artery; NA = not applicatle; } \mathrm{SA}= \\
\text { sulcal artery. } \\
\dagger \text { The number of sulcal arteries that bifurcated in the anterior median sulcus. } \\
\ddagger \text { One of these eight sulcal arteries shomed trifurcation. } \\
\text { \& Num ber of tifurcated sulcal arteries that supplied the spinal cord bilaterally. }\end{array}$} \\
\hline
\end{tabular}

The lateral branches of the anterior spinal artery coursed subpially over the anterior and lateral white columns. The mean number of these lateral branches was 1.6 per centimeter of cord (Table 2). Many of the lateral branches that reached the lateral columns connected subpially with branches of the posterior spinal arteries (Fig. 1 lower). Connections between lateral branches of the anterior spinal artery themselves also occurred on the lateral surface of the cord.

The anterior spinal vein ran alongside the anterior spinal artery in the anterior aspect of the sulcus, although the anterior spinal vein was generally situated slightly posterior to the anterior spinal artery. The anterior spinal vein received sulcal veins in the anterior median sulcus and superficial veins on the anterior surface.

Posterior Surface. The posterior spinal veins and the posterior spinal arteries were situated on the posterior pial surface in the subarachnoid space, and arachnoid trabeculae were identified along the posterior midline. In contrast, on the anterior surface the anterior spinal artery and veins were covered by pia mater and there were no trabeculae in the anterior subarachnoid space. The posterior spinal arteries were usually paired arterial channels that ran immediately medial or lateral to the posterior root entry zone on each side and connected with each other over the posterior surface through numerous communicating branches.

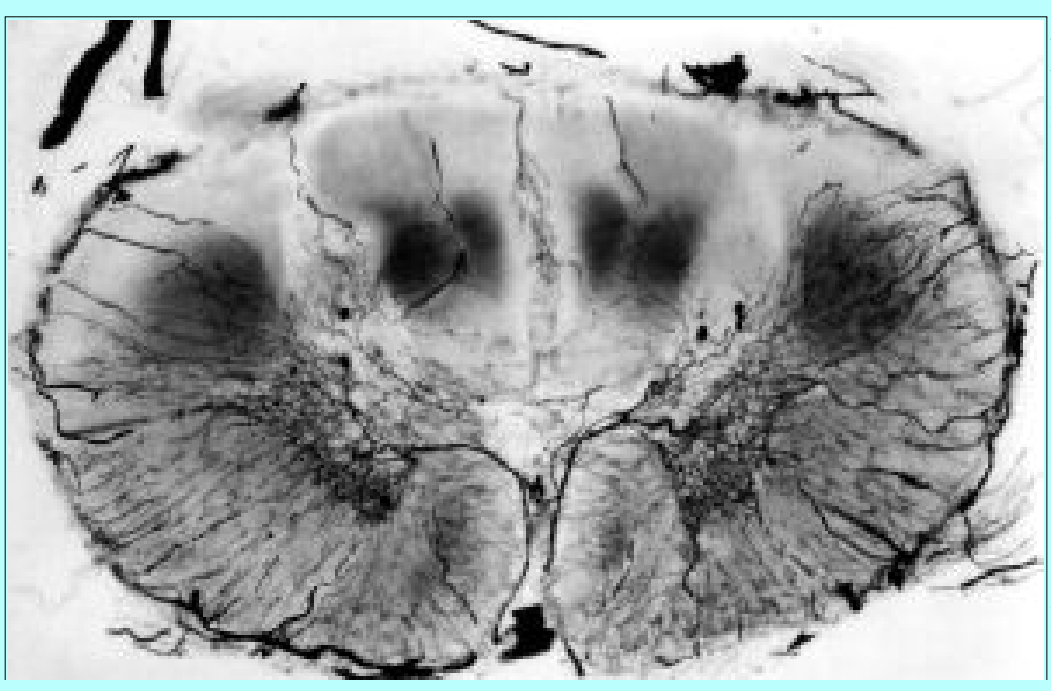

Fig. 2. Silicone rubber microangiograms of a nontraumatized spinal cord at the C-8 level after clearing away the tissue. Original magnification X 20. Upper: Transverse view clearly demonstrating intramedullary vessels, although the posterior gray matter and posterior white columns are partially filled. Center: Transverse view of the anterolateral spinal cord demonstrating a sulcal artery (SA) supplying the capillary network of the gray matter of the anterior 


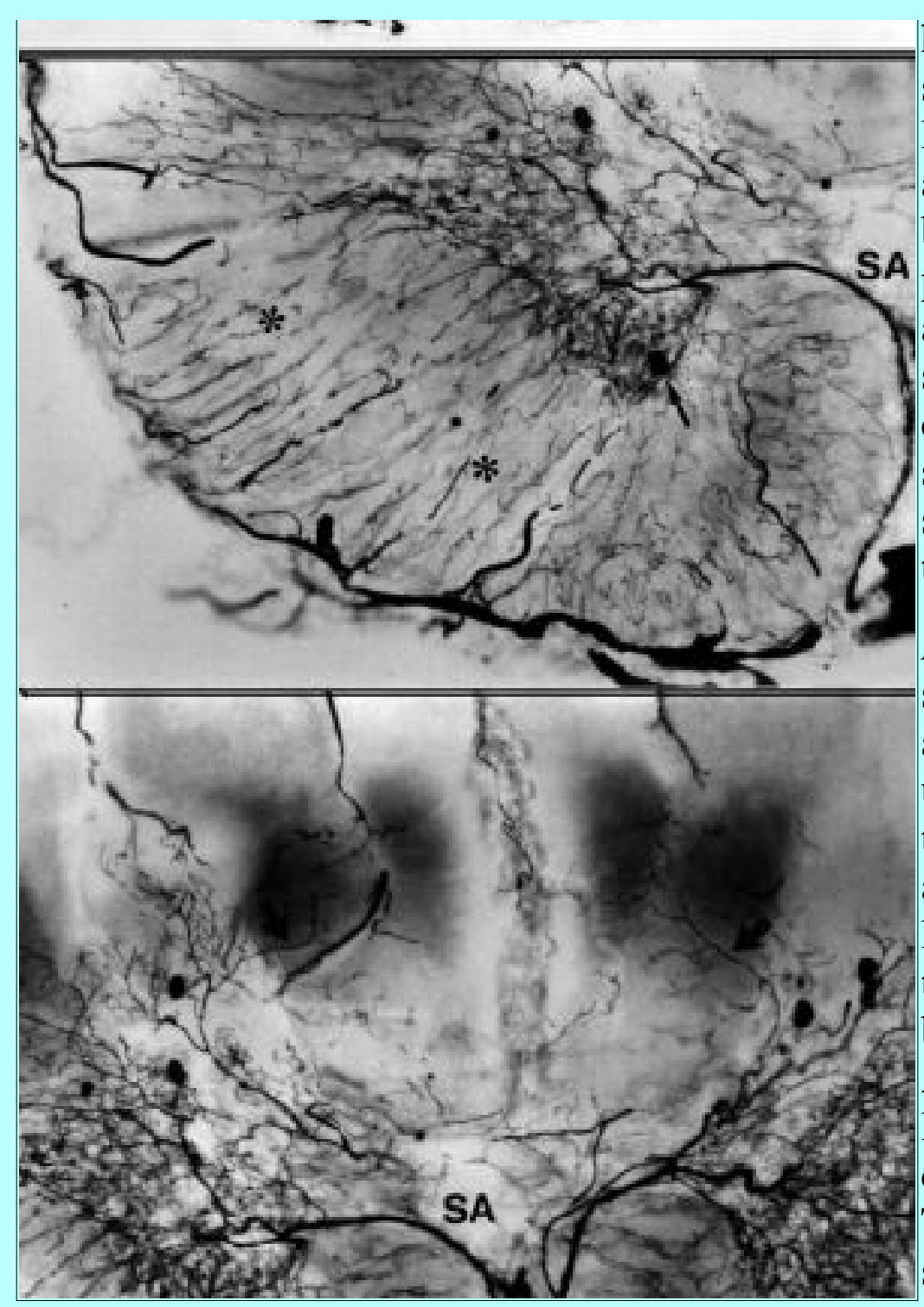

horn. The branches of the sulcal artery supply approximately the inner half of the lateral and anterior white matter. The asterisks indicate the watershed zone between the sulcal arterial system and the pial arterial system (seen to the left of the asterisks). The arrow indicates extravasated silicone. Lower: Transverse view of the central segment and posterior white columns showing that the branches (arrows) of the sulcal arteries (SA) extend into the base of the posterior white columns.

Intramedullary Vessels. The sulcal arteries supplied all of the anterior gray matter and the anterior part of the posterior gray matter (Fig. 2 upper). Branches of the sulcal arteries coursed through the gray matter and then supplied approximately the inner half of the anterior and lateral white columns (Fig. 2 center). The base of the posterior white columns was also supplied by branches from the sulcal arteries (Fig. 2 right). Approximately the outer half of the anterior and lateral white columns was supplied by the centripetal arterial system from the pial arteries. The posterior spinal arteries and their branches supplied the posterior part of the posterior gray matter and approximately the posterior half of the

posterior white columns.

The intramedullary veins were only partially filled with silicone rubber. The radial veins in the anterior and lateral white columns and the posterior septal veins in the posterior white columns were identified in two cords.

\section{Histological Analysis of Acute Spinal Cord Injury}

Immediate Period. In the patient who died approximately 20 minutes after he had been injured in a traffic accident (Case 1), the spinal cord was found to be transected at C1-2 due to atlantoaxial dislocation and a fractured odontoid process. Histological sections obtained from the $\mathrm{C}-1$ level showed an almost normal appearance except for multiple small hemorrhages in the gray matter (Fig. 3). 


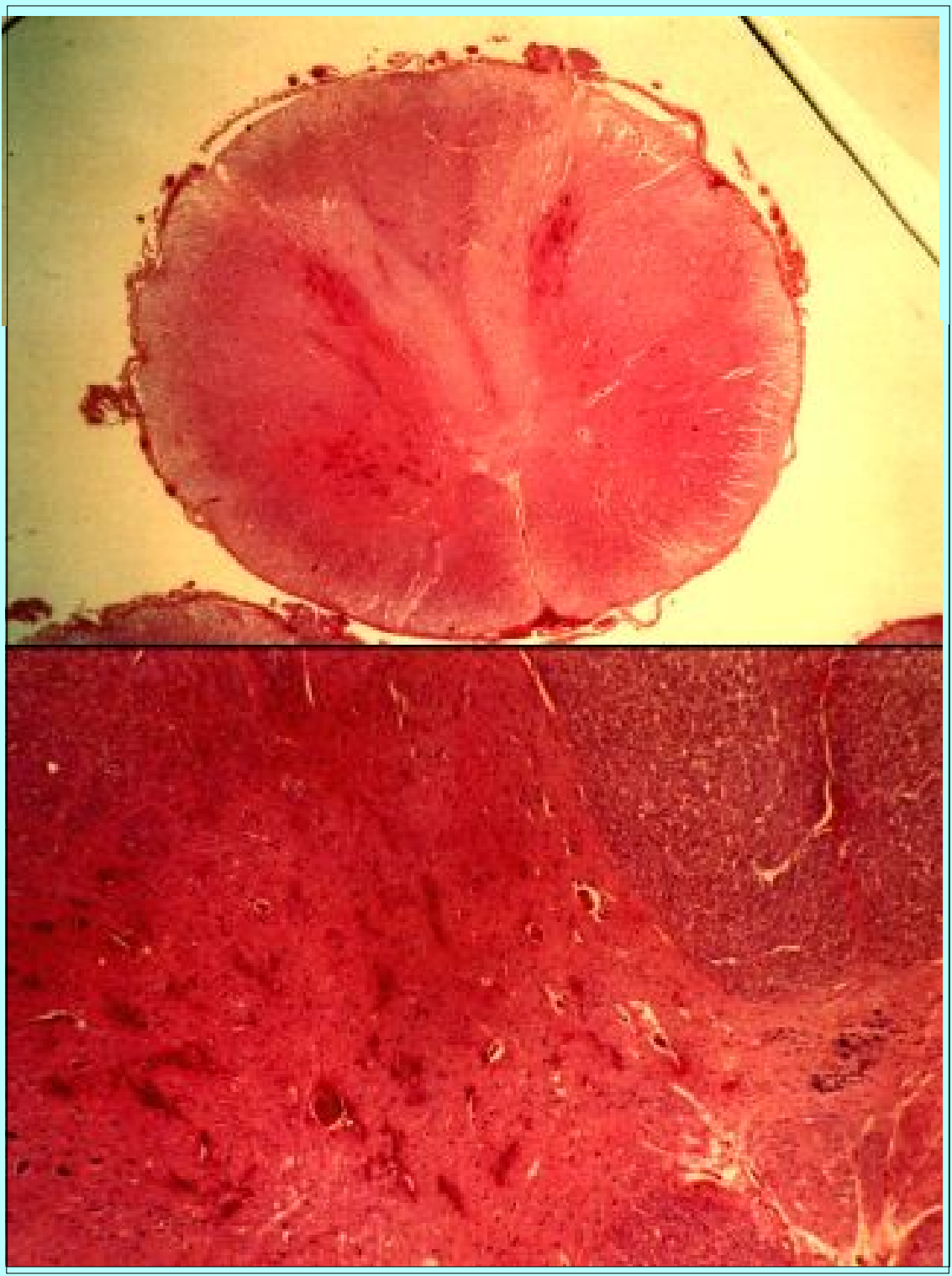

Fig. 3. Case 1. Photomicrographs showing a transverse section of the traumatized spinal cord in a patient who died shortly after a complete cord lesion due to atlantoaxial dislocation. $\mathrm{H} \& \mathrm{E}$. Upper: The spinal cord at the $\mathrm{C}-1$ level at low magnification (original magnification $X 7$ ) shows an almost normal appearance. Lower: Higher magnification (original magnification $\mathrm{X}$ 100) of this section reveals multiple small hemorrhages in the anterolateral gray matter.

Acute Phase. Two patients (Cases 2 and 3) died 3 and 5 days, respectively, after they had sustained spinal trauma as a result of brainstem infarction caused by traumatic occlusion of the vertebral artery. The patient in Case 2 had a C4-5 anterior dislocation and was treated surgically on the day of injury by open reduction, C4-5 laminectomy, posterior midline myelotomy, and hypothermic perfusion at the injured segment. Histological analysis of the traumatized segment in this case showed marked intramedullary hemorrhage that involved almost the whole spinal cord in the transverse plane (Fig. 4 upper left). The anterior spinal artery and sulcal artery at this level were patent, although the anterior spinal artery showed invasion of polymorphonuclear cells in the endothelial layer. At the adjacent level (approximately C-3) where the dura mater was intact and, hence, distant from the operated segment, the spinal cord showed decreased staining centrally with intact peripheral white matter (Fig. 4 upper right). The affected white matter in this level was almost totally necrotic, showing disrupted myelin, enlarged periaxonal spaces, swollen axons, and invasion of polymorphonuclear cells. Many intramedullary veins in the posterior white columns were occluded and filled with polymorphonuclear cells (Fig. 4 lower left). The gray matter showed major stagnation of flow with many small vessels packed with red blood cells, extravasation of red blood cells, and invasion of the tissue by polymorphonuclear cells. At the more rostral level (approximately C-2), the necrotic changes and red cell extravasation were more confined to the basal part of the posterior white columns and focal segments of the lateral white columns (Fig. 4 lower right). 


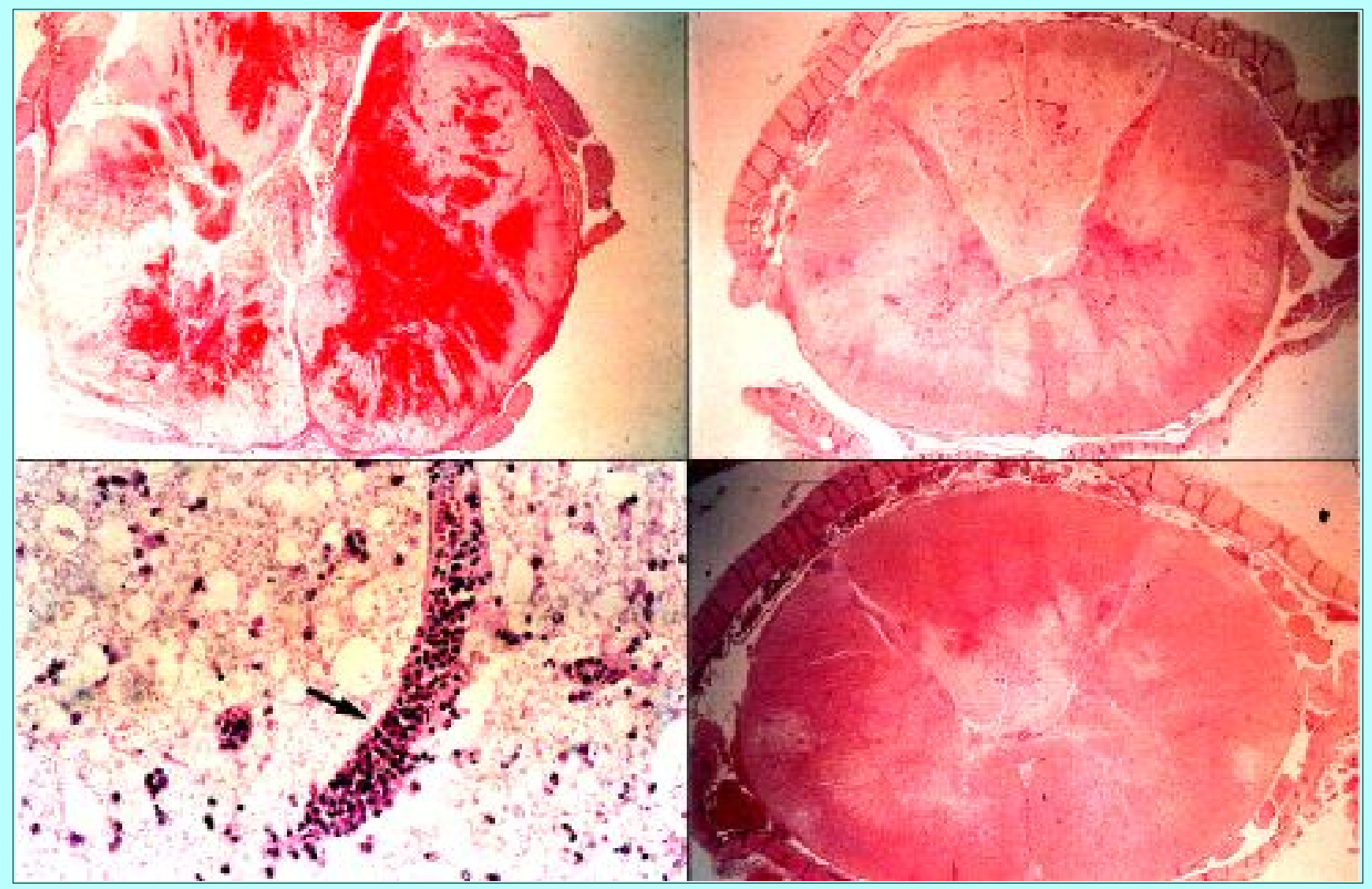

Fig. 4. Case 2. Photomicrographs displaying transverse sections of the traumatized spinal cord 3 days after complete cord lesion due to C4-5 anterior dislocation. H \& E. Upper Left: The injury site (C4-5 level) shows marked intramedullary hemorrhages in the gray and white matter. Original magnification X 7. Upper Right: The rostral segment of the cord at approximately the C-3 level shows decreased staining in the gray matter and the central half of the white matter. There was preservation of the peripheral white matter. There were no hemorrhages. Original magnification X 7. Lower Left: Higher magnification of a portion of central white matter of the posterior columns of the section shown in upper right. The veins were occluded with polymorphonuclear cells (arrow) and the central white matter was totally necrotic with many polymorphonuclear cells identified in this area. Original magnification X 400. Lower Right: A portion of the cord farther rostral to that seen in upper right, at approximately the C-2 level. The central areas of decreased staining are much smaller than those seen in upper right and were confined to the base of the posterior white columns and part of the lateral white matter. Original magnification X 7 .

In Case 3, in which the patient had suffered a C4-5 fracture dislocation and an incomplete cord lesion (complete loss of distal motor function, but sparing of sacral sensation), the gray matter of the injured segment showed numerous hemorrhages and the white matter surrounding the hemorrhagic gray matter showed extensive necrosis (Fig. 5). Much of the peripheral white matter showed a more normal appearance with persisting myelinated axons in the subpial rim of tissue. There was no evidence of occlusion of the anterior spinal artery or sulcal arteries.

Fig. 5. Case 3. Photomicrograph showing the traumatized spinal cord at the C-4 level 5 days after an incomplete cord injury due to a 


$\mid \begin{aligned} & \text { C4-5 fracture dislocation. Multiple } \\ & \text { hemorrhages are confined to the gray matter. } \\ & \text { The white matter adjacent to the } \\ & \text { hemorrhagic gray matter shows decreased } \\ & \text { staining, whereas the subpial peripheral } \\ & \text { white matter of the lateral and posterior } \\ & \text { columns is preserved. H \& E and luxol fast } \\ & \text { blue, original magnification X } 7 \text {. }\end{aligned}$

Subacute Phase. The patient in Case 4 died due to acute pulmonary embolism at 17 days and the patient in Case 5 died of acute bronchopneumonia at 18 days after sustaining spinal trauma. Cases 4 and 5 did not show any discernible normal white matter at the injury site, even in the subpial rim. The tissue was completely replaced by lipid laden phagocytic cells that frequently contained hemosiderin. Many dilated small vessels were also identified (Fig. 6), which were most likely new vessels proliferating into the necrotic tissue. At adjacent levels, the white matter showed varying degrees of degeneration with a variety of degenerative axonal changes, including enlargement of the periaxonal spaces and swollen giant axons.

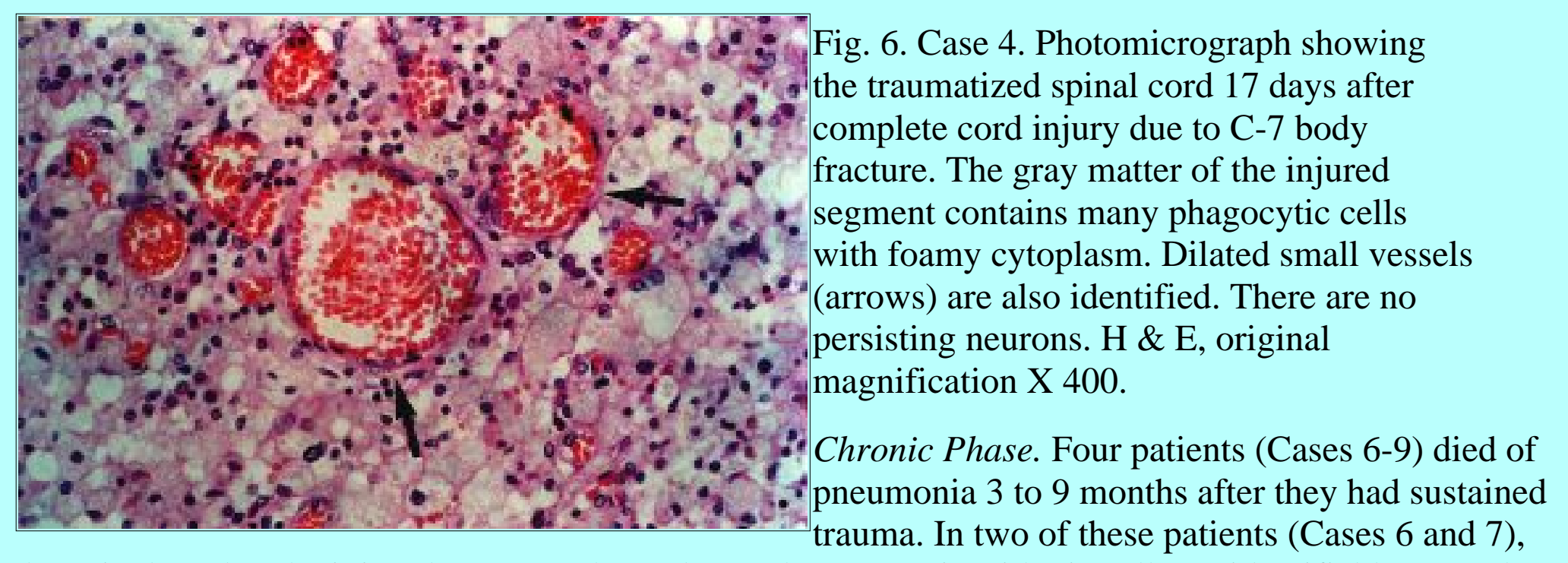

the spinal cord at the injured segment showed complete necrosis with virtually no identifiable normal gray or white matter even at the subpial rim (Fig. 7 upper), although there was some gliosis and many phagocytic cells. In two patients (Cases 8 and 9), there was some remaining peripheral white matter. At the adjacent rostral and caudal segments, 1 to $2 \mathrm{~cm}$ remote from the injury site, the base of the posterior columns contained clearly demarcated areas of necrosis that were highly suggestive of discrete infarcts (Fig. 7 lower). In these remote necrotic areas, there was no evidence of previous hemorrhage such as deposits of hemosiderin. Similar remote discrete infarcts were also observed in the lateral white matter in one case. Clusters and nests of proliferating Schwann cells were observed in the posterior and anterior white columns at the injury site in two cases (Cases 8 and 9).

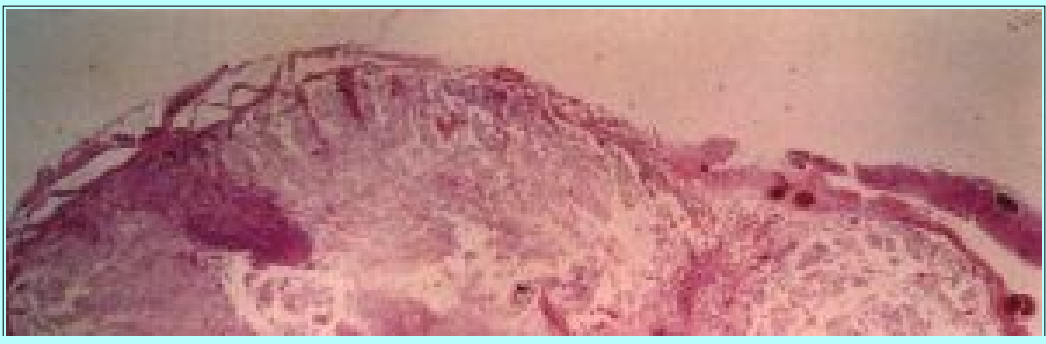

Fig. 7. Case 7. Photomicrographs displaying the traumatized spinal cord 3 months after complete cord injury due to C5-6 fracture dislocation. Upper: The injured segment shows marked necrosis and disorganization 


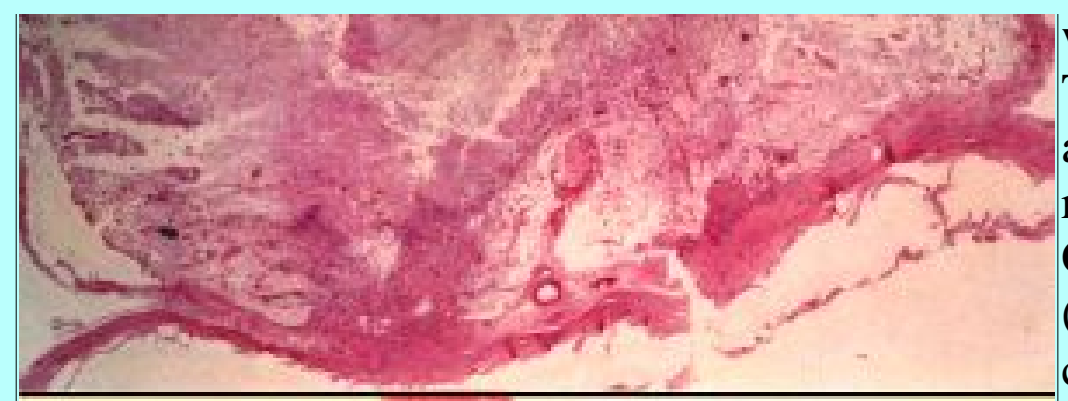

with virtually no identifiable gray matter. The anterior spinal artery at the lowermost aspect of the specimen was patent. Lower: A rostral segment of the cord at approximately C-3. Well-demarcated necrotic areas (arrows), which have the appearance of circumscribed infarcts, are seen at the base of the posterior white columns. The more

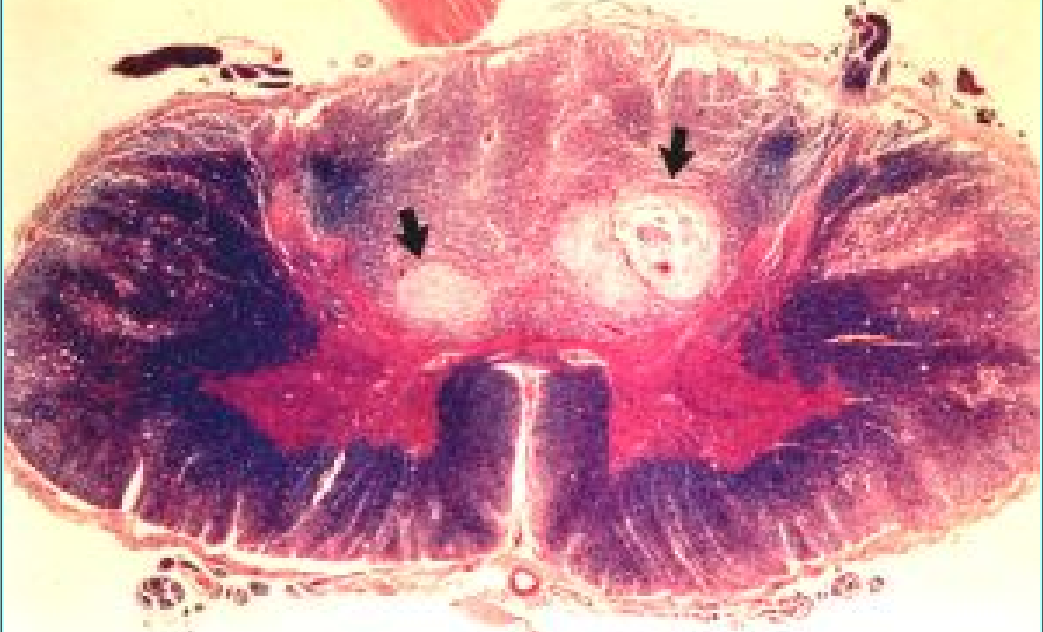
external portion of the posterior white columns shows Wallerian degeneration. H \& $\mathrm{E}$ and luxol fast blue, original magnification $\mathrm{X} 7$.

\section{DISCUSSION}

Blood Supply to the Human Spinal Cord

The aim of examining the blood supply to the human spinal cord using three-dimensional silicone rubber microangiography was to obtain information for determining the pathophysiology of major vascular lesions in human spinal cord injury. There have been many excellent studies of the blood supply of the human spinal cord, which have demonstrated the centrifugal supply from the sulcal arteries, the centripetal supply from the posterior spinal and pial arteries, and the intervening watershed zones supplied through both routes.[3,12,14,15,22,40-43] The present three-dimensional study confirms this arrangement. We also demonstrated the origin of the pial arteries as lateral branches from the anterior spinal artery and that these communicate extensively with lateral branches originating from the posterior spinal arteries. The sulcal arteries, which number approximately four to five per centimeter of cervical cord, often bifurcate in the anterior median sulcus. These findings are also similar to those described by other authors. [42,43] However, the descriptions of the pattern of the intramedullary arterial supply in the human spinal cord have differed among the authors. According to Turnbull and colleagues[41,42] and Lazorthes, et al.,[22] the sulcal arteries supply most of the gray matter and also the base of the posterior white columns (Fig. 8). These authors showed that the overlap between the zones of supply from the centrifugal sulcal arteries and the centripetal penetrating arteries is located at the junction of the outer border of the gray matter and adjacent white matter. Furthermore, these reports showed that most of the white lateral columns are supplied only by the penetrating branches from the pial arterial plexus. In contrast, according to Gillilan's[12] study, the penetrating arteries from the pial arteries supply the outer rim of the white matter and the overlapping area, which is much larger than that found by Turnbull and colleagues, and comprises the outer rim of the gray matter and the inner two-thirds of the white matter in the lateral and anterior spinal cord (Fig. 8). Herren and Alexander[15] reported that the lateral corticospinal tract is nourished by branches of the sulcal arteries, a finding supported by the present study. Although some of the differences in observations by previous investigators might be due to variations in vasculature in different spinal cord specimens, it is more likely that the discrepancies are due to the difficulties in differentiating arteries from veins inherent in the postmortem two-dimensional microangiographic techniques used in previous studies. The lack of three-dimensional observation is also likely to have produced misinterpretation of the zones of supply. In contrast, the three-dimensional silicone rubber microangiographic technique used in the present study allows accurate mapping of the 
extent of supply and also is of major benefit in differentiating arteries and veins. Also, our injection technique fills mainly the arterial system and capillaries; this aided our differentiation between arteries and veins. The present results prove that the sulcal arterial system supplies all the anterior gray matter, the anterior half of the posterior gray matter, approximately the inner half of the anterior and lateral white matter columns, and the anterior half of the posterior white columns (Fig. 8). It is of interest that the distribution of peripheral white matter lesions caused by a pial arterial circulatory disturbance in the two autopsy cases of systemic lupus erythematosus reported by Nakano, et al.,[25] is consistent with our findings concerning the pattern of vascular supply in the cord.

\section{Turnbull}

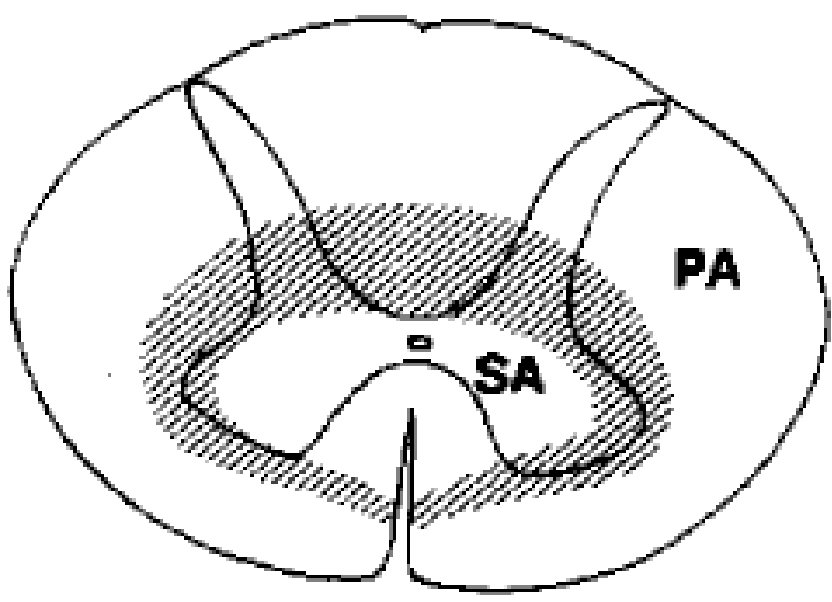

\section{Gillilan}

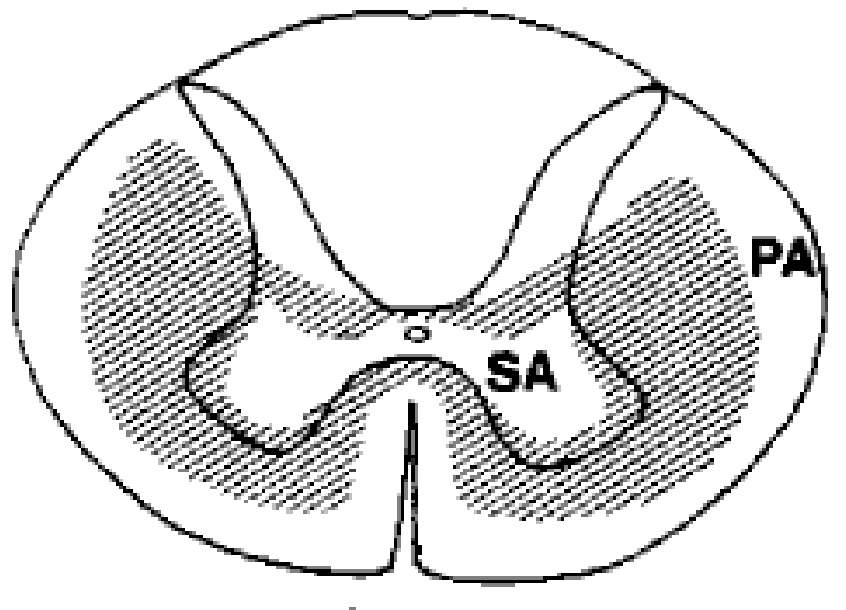

The Present Study

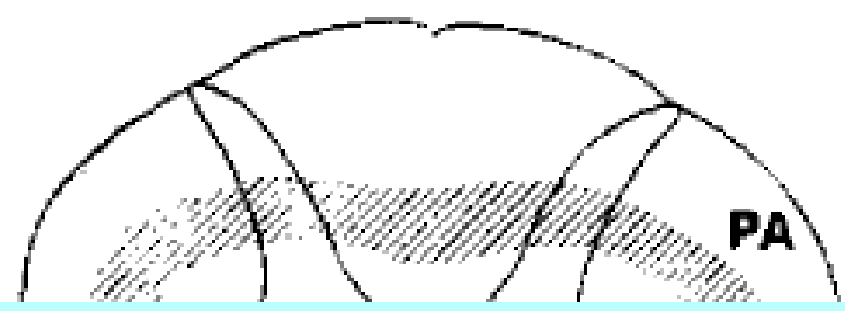

Fig. 8. Diagrams diplaying patterns of arterial supply in the normal human cervical cord. The central area is supplied by the centrifugal arterial system composed of branches of the sulcal arteries (SA). The peripheral white matter and the posterior portion of the posterior gray matter are supplied by the centripetal arterial system composed of branches of the posterior spinal arteries and the pial arteries (PA). The shaded area shows the overlap or watershed zone between the centrifugal and centripetal arterial systems. Note the differences in the patterns of arterial supply between previous authors and the present study. The present findings indicate that the centrifugal system supplies most of the gray matter and the medial white matter of the anterior, lateral, and posterior white columns.

\section{Histology and Pathophysiology of Vascular Lesions in Human Spinal Cord Injury}

Although the present study included only one case examined in the 1st hour after injury, in the literature there are several cases examined within the first 24 hours after severe spinal cord injury that have shown petechial and more confluent hemorrhages in much of the gray matter. The absence of cellular and tissue necrosis in the early period has been reported in several studies of human spinal cord injury. $[16-18,23]$ Thereafter, there is evidence for a progressive necrotizing process. In the present study, specimens examined 3 to 5 days after injury showed severe tissue necrosis and an inflammatory cell infiltration that affected the gray matter and extended out into the white matter. Our study confirmed that none of the major arteries on the surface of the human spinal cord, including the anterior and posterior spinal arteries, are occluded at the injury site or remotely at any time after trauma. This finding corresponds to those of our previous 


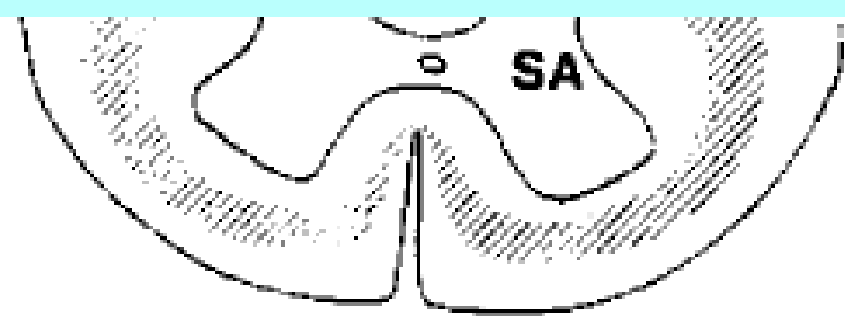

microangiographic studies[20,21,45] in a rat model of spinal cord injury in which there was extensive occlusion and vasospasm of intramedullary vessels, but patency of the large arteries at all times after injury. Jellinger[16] also reported that in human spinal cord injury traumatic occlusion or thrombosis of the major arteries on the surface of the cord is extremely rare. These findings lead to the conclusion that the location of vascular damage in human spinal cord injury is primarily in the intramedullary vascular system.

It is of major interest that the supply territory of the sulcal arteries, as defined by the microangiographic study, corresponds very closely to the distribution of both the hemorrhagic necrosis in the acute phase and the central myelomalacia and cavitation of the later phases, which involve most of the gray matter and at least the inner half of the white matter of the anterior, lateral, and posterior columns. Thus, the site of the major arterial injury implicated in acute spinal cord trauma is the anterior sulcal artery within a short distance from its origin at the anterior spinal artery. To produce the extensive bilateral areas of damage in the rostral-caudal plane, which were seen in most of the cases of acute spinal cord injury examined in the present study, would require damage to several anterior sulcal arteries because these arteries supply alternate sides of the cord and overlap with two or three sulcal arteries supplying each destination. We found an average of 4.6 sulcal arteries per centimeter of cord and estimate that to produce a complete cord injury, such as that shown in Fig. 4 upper right, would likely involve damage to approximately $1 \mathrm{~cm}$ of cord tissue containing two or three sulcal arteries supplying blood to each side. Incomplete cord injuries, such as that shown in Fig. 5, might occur from shorter lengths of damaged cord containing only one or two sulcal arteries on each side. Occlusion of the sulcal arteries more distally would allow greater preservation of the anterior parts of the cord (Fig. 5), which would continue to receive blood through persisting small branches of the sulcal artery arising in the anterior median sulcus. Thus, our findings also suggest that less severe injuries would damage the sulcal arteries distally, whereas more severe injuries would damage the sulcal arteries proximally. The exact nature of the arterial damage could be direct mechanical damage or a secondary process such as vasospasm.

It is acknowledged that there are alternative explanations for central hemorrhagic necrosis and central myelomalacia. For example, it could be hypothesized that the principle anatomical site of vascular injury is the endothelial cells of capillaries, either by direct mechanical trauma or secondary to ischemia. In turn, endothelial cell damage would result in hemorrhage and then infarction. However, this concept of endothelial cell capillary damage is less consistent with the anatomical distribution of central hemorrhagic necrosis and myelomalacia than the sulcal artery hypothesis.

In the present study, at the injury site the gray matter was more prone to be hemorrhagic, whereas most of the white matter showed nonhemorrhagic degenerative changes including decreased staining, periaxonal and axonal swelling, and disruption of myelin in the acute stage (3-5 days postinjury). These white matter lesions were distributed around the hemorrhagic gray matter and extended rostrally and caudally from the injury site, especially in the posterior white columns. It is highly likely that these nonhemorrhagic white matter lesions progress in time to become the well-demarcated necrotic white matter areas in the later stages that have the histological appearance of infarcts. The predominance of hemorrhages in the gray matter can be explained on the basis of the rich capillary network in the gray matter, the latter being highly susceptible to mechanical stress because of its looser, more yielding texture. The surrounding white matter lesions may be partly explained by the centrifugal vascular supply of the sulcal arteries. As noted above, silicone rubber microangiograms showed that the inner half of the 
white matter was predominantly supplied by small arterial branches from the sulcal arteries, which course through the gray matter to reach the white matter. Thus, it is highly likely that interference with the sulcal centrifugal arterial system in the gray matter leads to a subsequent interruption of blood flow to the inner half of the white matter. Similar to the above discussion about proximal and distal sulcal artery damage, the possible mechanisms of interference with these "en passage" smaller branches of the sulcal arteries would include direct mechanical or secondary damage (Fig. 9). There is experimental evidence for the concept of secondary vascular damage involving the centripetal sulcal system. For example, we found a direct relationship between hemorrhagic gray matter and adjacent ischemic zones in the white matter in rats after acute clip-compression injury studied with colloidal carbon angiography.[45] Also, our laboratory previously showed vasospasm of the sulcal arteries[20] in similarly injured rats studied with polyester resin and scanning electron microscopy.

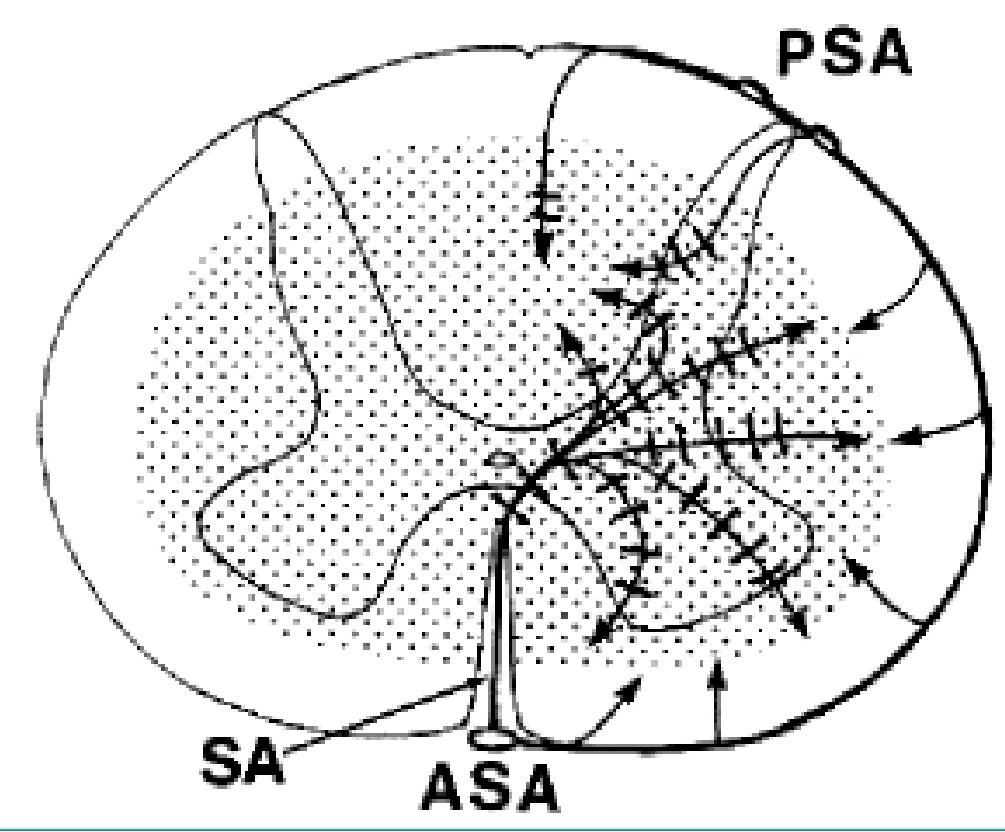

Fig. 9. Diagram showing vessels that would be affected to produce the histological appearance of major central necrosis (stippled area) with a subpial rim of surviving white matter. Hemorrhages are not shown. The lines across the arrows indicate damaged vessels. ASA = anterior spinal artery; PSA = posterior spinal artery; $\mathrm{SA}=$ sulcal artery.

Our laboratory and others have also postulated that ischemia of the posterior white columns can be produced by disturbances of venous drainage in the acutely traumatized spinal cord.[20,21,35,36] Support for this hypothesis comes from observations that venous occlusion in the spinal cord in various pathological conditions causes predominantly white matter lesions.[19,28,30] With a weight-drop model of mild spinal cord injury, Dohrmann and associates[6] reported that disruption of the muscular venules in the gray matter occurs early after trauma in primates. In the present study, we found occluded veins filled with polymorphonuclear cells in the degenerated posterior white columns in the acute stage (Case 2). However, it was not possible to determine whether the venous occlusion was caused by direct mechanical damage of the veins or was secondary to arterial or capillary occlusion. In our opinion, it is highly likely that venous damage, either direct or secondary, contributes significantly to the nonhemorrhagic white matter lesions. Our previous studies of veins in rats with spinal cord injury using silicone rubber angiography demonstrated several anatomical features that make these veins suceptible to occlusion during compression injury.[21] Unfortunately, the present study did not provide sufficient opportunity to study the anatomy of the venous drainage to determine if there are similar anatomical features in the human cord.

The distribution of mechanical stress in the traumatized spinal cord could be another important factor affecting the vasculature to cause the extensive white matter lesions. Blight and Decrescito[2] used silastic tubing filled with gelatin as a physical model of the spinal cord to demonstrate that an anteroposterior compressive force on the tube produces longitudinal stress that is most intense in the center of the tube. Because the pia mater is a strong membrane, the large vessels on the surface of the 
spinal cord and in the anterior median sulcus would be relatively spared from major damage due to mechanical stress exerted in the anteroposterior direction. However, the smaller intramedullary vessels would be stretched in the longitudinal plane. Differences in compliance in the spinal cord may produce a shearing stress on microvessels that form a bridge between the gray and white matter. Such a stretching force and shearing stress may obstruct the microvessels directly, or initiate secondary pathological responses in the vascular walls, such as platelet aggregation or invasion by polymorphonuclear cells, which subsequently lead to vascular occlusion.

McVeigh[24] postulated that necrotic, pulped spinal cord tissue produced in the traumatized segment could invade longitudinally and travel rostrally and caudally in the center of the cord. He considered that the remote lesions in the posterior white columns are caused by invasion of the pulped mass. We saw no evidence of this process in our cases. For example, there was no evidence of hemorrhagic tissue in these remote areas of necrotic white matter in the acute stage, and there was no evidence of previous hemorrhage in the necrotic white matter in the chronic stage.

Recently, Quencer, et al.,[29] and Bunge, et al.,[4] reported excellent studies of the pathological findings of the traumatized spinal cord in humans. In particular, they showed a lack of hemorrhage in the gray and white matter in several cases of central cord syndrome. Instead, they found major axonal injury in the lateral corticospinal tracts which they attributed to anteroposterior compression forces. Although they did not mention the possibility of a vascular mechanism of injury, our studies suggest that stretching or compression of the centrifugal sulcal branches might result in occlusion or constriction of these vessels supplying the corticospinal tracts.

Further investigation is necessary to elucidate the pathophysiology of hemorrhagic gray matter lesions and nonhemorrhagic white matter lesions in acute spinal cord injury in humans. To date, our investigations provide evidence of the importance of the centrifugal sulcal arterial system, which may be the principal site of the primary direct mechanical injury and the secondary mechanisms of injury, some of which (such as vasospasm) may be delayed and amenable to treatment.

\section{Acknowledgments}

We thank Dr. John H. N. Deck, Division of Neuropathology, Department of Pathology, The Toronto Hospital, for providing the histological material in the cases of acute spinal cord injury, and Dr. Peter Dirks for helping to prepare the cervical cord specimens for microangiography. Grateful acknowledgement is also made to Mr. Jim Loukides for his technical assistance.

\section{References}

1. Allen WE III, D'Angelo CM, Kier EL: Correlation of microangiographic and electrophysiologic changes in experimental spinal cord trauma. Radiology 111:107-115, 1974

2. Blight AR, Decrescito V: Morphometric analysis of experimental spinal cord injury in the cat: the relation of injury intensity to survival of myelinated axons. Neuroscience 19:321-341, 1986

3. Bolton B: The blood supply of the human spinal cord. J Neurol Psychiatry 2:137-148, 1939

4. Bunge RP, Puckett WR, Becerra JL, et al: Observations on the pathology of human spinal cord injury. A review and classification of 22 new cases with details from a case of chronic cord compression with 
extensive focal demyelination. Adv Neurol 59:75-89, 1993

5. Dohrmann GJ, Allen WE III: Microcirculation of traumatized spinal cord. A correlation of microangiography and blood flow patterns in transitory and permanent paraplegia. J Trauma 15:1003-1013, 1975

6. Dohrmann GJ, Wagner FC Jr, Bucy PC: The microvasculature in transitory traumatic paraplegia. An electron microscopic study in the monkey. J Neurosurg 35:263-271, 1971

7. Dohrmann GJ, Wick KM, Bucy PC: Spinal cord blood flow patterns in experimental traumatic paraplegia. J Neurosurg 38:52-58, 1973

8. Fairholm DJ, Turnbull IM: Microangiographic study of experimental spinal cord injuries. J Neurosurg 35:277-286, 1971

9. Fehlings MG, Tator $\mathrm{CH}$, Linden RD: The effect of nimodipine and dextran on axonal function and blood flow following experimental spinal cord injury. J Neurosurg 71:403-416, 1989

10. Fehlings MG, Tator $\mathrm{CH}$, Linden RD: The relationship among the severity of spinal cord injury, motor and sensory evoked potentials and spinal cord blood flow. Electroencephalog Clin Neurophysiol 74:241-259, 1989

11. Fried LC, Goodkin R: Microangiographic observations of the experimentally traumatized spinal cord. J Neurosurg 35:709-714, 1971

12. Gillilan LA: The arterial blood supply of the human spinal cord. J Comp Neurol 110:75-103, 1958

13. Guha A, Tator CH, Rochon J: Spinal cord blood flow and systemic blood pressure after experimental spinal cord injury in rats. Stroke 20:372-377, 1989

14. Hassler O: Blood supply to human spinal cord. A microangiographic study. Arch Neurol 15:302-307, 1966

15. Herren RY, Alexander L: Sulcal and intrinsic blood vessels of human spinal cord. Arch Neurol Psychiatry 41:678-687, 1939

16. Jellinger K: Neuropathology of cord injuries, in Vinken PJ, Bruyn GW (eds): Handbook of Clinical Neurology. Vol 25: Injury of the Spine and Spinal Cord. Part 1. Amsterdam: North-Holland, 1976, pp 43-121

17. Kakulas BA: Pathology of spinal injuries. Cent Nerv Syst Trauma 1:117-129, 1984

18. Kakulas BA, Taylor JR: Pathology of injuries of the vertebral column and spinal cord, in Vinken PJ, Bruyn GW, Klawans HL, Frankel HL (eds): Handbook of Clinical Neurology. Vol 61: Spinal Cord Trauma. Amsterdam: North-Holland, 1992, pp 21-51

19. Kim RC, Smith HR, Henbest ML, et al: Nonhemorrhagic venous infarction of the spinal cord. Ann Neurol 15:379-385, 1984

20. Koyanagi I, Tator CH, Lea PJ: Three-dimensional analysis of the vascular system in the rat spinal cord with scanning electron microscopy of vascular corrosion casts. Part 2: Acute spinal cord injury.

Neurosurgery 33:285-292, 1993 
21. Koyanagi I, Tator CH, Theriault E: Silicone rubber microangiography of acute spinal cord injury in the rat. Neurosurgery 32:260-268, 1993

22. Lazorthes G, Gouaze A, Zadeh JO, et al: Arterial vascularization of the spinal cord. Recent studies of the anastomotic substitution pathways. J Neurosurg 35:253-262, 1971

23. Liss L: Fatal cervical cord injury in a swimmer. Neurology 15:675-677, 1965

24. McVeigh JF: Experimental cord crushes with especial reference to the mechanical factors involved and subsequent changes in the areas of the cord affected. Arch Surg 7:573-600, 1923

25. Nakano I, Mannen T, Mizutani T, et al: Peripheral white matter lesions of the spinal cord with changes in small arachnoid arteries in systemic lupus erythematosus. Clin Neuropathol 8:102-108, 1989

26. Nelson E, Gertz SD, Rennels ML, et al: Spinal cord injury. The role of vascular damage in the pathogenesis of central hemorrhagic necrosis. Arch Neurol 34:332-333, 1977

27. Nemecek S: Morphological evidence of microcirculatory disturbances in experimental spinal cord trauma. Adv Neurol 20:395-405, 1978

28. Ohshio I, Hatayama A, Kaneda K, et al: Correlation between histopathologic features and magnetic resonance images of spinal cord lesions. Spine 18:1140-1149, 1993

29. Quencer RM, Bunge RP, Egnor M, et al: Acute traumatic central cord syndrome: MRI-pathological correlations. Neuroradiology 34:85-94, 1992

30. Rao KR, Donnenfeld H, Chusid JG, et al: Acute myelopathy secondary to spinal venous thrombosis. J Neurol Sci 56:107-113, 1982

31. Reed JE, Allen WE III, Dohrmann GJ: Effect of mannitol on the traumatized spinal cord.

Microangiography, blood flow patterns, and electrophysiology. Spine 4:391-397, 1979

32. Rivlin AS, Tator CH: Regional spinal cord blood flow in rats after severe cord trauma. J Neurosurg 49:844-853, 1978

33. Sandler AN, Tator CH: Review of the effect of spinal cord trauma on the vessels and blood flow in the spinal cord. J Neurosurg 45:638-646, 1976

34. Sasaki S: Vascular change in the spinal cord after impact injury in the rat. Neurosurgery 10:360-363, 1982

35. Schneider H: Acute and chronic pathomorphological reactions to cord injury. in Schramm J, Jones SJ (eds): Spinal Cord Monitoring. Berlin: Spring-Verlag, 1985, pp 103-120

36. Shingu H, Kimura I, Nasu Y, et al: Microangiographic study of spinal cord injury and myelopathy. Paraplegia 27:182-189, 1989

37. Tator CH: Ischemia as a secondary neural injury, in Salzman SK, Faden AI (eds): The Neurobiology of Central Nervous System Trauma. New York: Oxford University Press, 1994, pp 209-215

38. Tator CH: Review of experimental spinal cord injury with emphasis on the local and systemic circulatory effects. Neurochirurgie 37:291-302, 1991 
39. Tator CH: Spinal cord cooling and irrigation for treatment of acute cord injury, in Popp AJ, Bourke RS, Nelson LR, et al (eds): Neural Trauma. Seminars in Neurological Surgery Series. New York: Raven Press, 1979, pp 363-369

40. Tator $\mathrm{CH}$, Fehlings MG: Review of the secondary injury theory of acute spinal cord trauma with emphasis on vascular mechanisms. J Neurosurg 75:15-26, 1991

41. Turnbull IM: Microvasculature of the human spinal cord. J Neurosurg 35:141-147, 1971

42. Turnbull IM, Brieg A, Hassler O: Blood supply of cervical spinal cord in man. A microangiographic cadaver study. J Neurosurg 24:951-965, 1966

43. Tveten L: Spinal cord vascularity. III. The spinal cord arteries in man. Acta Radiol (Diagn) 17:257-273, 1976

44. Vlajic I: Microangiographic observations of morphological vessel changes after experimental spinal cord trauma. Adv Neurol 20:451-460, 1978

45. Wallace MC, Tator $\mathrm{CH}$, Frazee P: Relationship between posttraumatic ischemia and hemorrhage in the injured rat spinal cord as shown by colloidal carbon angiography. Neurosurgery 18:433-439, 1986

Manuscript received September 18, 1995.

Accepted in final form September 24, 1996.

This work was supported by the Canadian Paraplegic Association, Ontario Branch, the Samuel Lunenfeld Research Foundation, and the Medical Research Council of Canada. During the course of this study, Dr. Koyanagi was a Fellow of the Rick Hansen Man in Motion Legacy Fund.

Address for Dr. Koyanagi: University of Hokkaido School of Medicine, Sapporo, Japan.

Address reprint requests to: Charles H. Tator, M.D., Ph.D., Division of Neurosurgery, The Toronto Hospital, Western Division, 399 Bathurst Street, McLaughlin Pavilion 2-435, Toronto, Ontario, Canada, M5T 2S8. 